WILLI SEBASTIAN KÜNZLI

INVESTIMENTO ESTRANGEIRO EM TERRAS NO BRASIL À LUZ DO DIREITO INTERNACIONAL

\author{
Dissertação de Mestrado \\ Orientador: Professor Titular Dr. Paulo Borba Casella
}

UNIVERSIDADE DE SÃO PAULO

FACULDADE DE DIREITO

São Paulo-SP

2014 


\section{INVESTIMENTO ESTRANGEIRO EM TERRAS NO BRASIL À LUZ DO DIREITO INTERNACIONAL}

Dissertação apresentada à Banca Examinadora do Programa de Pós-Graduação em Direito, da Faculdade de Direito da Universidade de São Paulo, como exigência parcial para obtenção do título de Mestre em Direito, na área de concentração Direito Internacional, sob a orientação do Professor Titular Dr. Paulo Borba Casella.

Banca Examinadora:

Data da Aprovação:

UNIVERSIDADE DE SÃO PAULO

FACULDADE DE DIREITO

São Paulo-SP

2014 


\section{Resumo}

KÜNZLI, Willi Sebastian. Investimento Estrangeiro em Terras No Brasil À Luz do Direito Internacional. f. 168. Dissertação (Mestrado) - Faculdade de Direito, Universidade de São Paulo, São Paulo.

Este trabalho tem como objeto a análise do investimento estrangeiro em terras no Brasil à luz do Direito Internacional. É abordado inicialmente o histórico do investimento estrangeiro desde a época da chegada dos portugueses no território Brasileiro. Nessa oportunidade, são descritos os instrumentos legais utilizados para inicialmente atrair e, posteriormente, restringir o investimento estrangeiro em terras no Brasil ao longo da história, analisando-se inclusive o momento econômico e histórico pelo qual o País passava. Passa-se então à apreciação do atual estado da legislação nacional sobre a matéria, abordando-se inclusive as interpretações divergentes que resultaram na liberalização e posterior restrição ao investimento estrangeiro. Uma vez esclarecido o panorama e regime jurídico do investimento em terras no Brasil, o trabalho passa a abordar a forma como instrumentos internacionais trataram do assunto, fazendo uma análise de Acordos Bi- e Multilaterais que regulam a matéria e dos impactos para os seus signatários. É identificada a posição do Brasil perante a regulação internacional da matéria, o qual possui apenas um acordo internacional em vigor com Portugal, garantindo aos portugueses as mesmas condições para aquisição de terras no Brasil que aos brasileiros. Ainda quanto ao direito internacional, descreve-se o fenômeno da apropriação de terras (conhecido internacionalmente como land grab, land grabbing ou farmland grab), a discussão em torno do assunto, as áreas atingidas e as pesquisas desenvolvidas pelos organismos internacionais. A partir dessa análise expõe-se das pesquisas realizadas no Brasil e internacionalmente sobre a relação entre $o$ desenvolvimento econômico, social e ambiental e a apropriação de terras por estrangeiros, bem como a posição do Brasil perante a isso. Conclui-se, por fim, que a regulação do investimento estrangeiro em terras no Brasil merece passar por uma reforma que traga mais segurança jurídica suprindo e retirando os espaços existentes para interpretações divergentes.

Palavras Chave: Investimento Estrangeiro, Terras, Brasil, Direito Internacional, Desenvolvimento. 


\begin{abstract}
KÜNZLI, Willi Sebastian. Investimento Estrangeiro em Terras No Brasil À Luz do Direito Internacional [Foreign Investment in Land in Brazil in Light of International Law]. 168 pages. Dissertation (Master's Degree) - Faculty of Law, University of São Paulo, São Paulo.

This thesis serves the purposes of analyzing the foreign investment in land in Brazil in light of International Law. Initially, it describes the history of international investment in Brazil since the arrival of the Portuguese in Brazilian territory. This analysis touches upon the legal framework designed to originally attract and, afterwards, restrict foreign investment in Brazilian land throughout history, taking into account the economic and social moment that the Country was going through. Then, it analyzes the current interpretation of the national laws over the subject, including the contradictory set of understandings of the law, which resulted in the liberalization and subsequent restriction to foreign investment. Once the history and the legal framework of foreign investment in land acquisitions in Brazil are established, this thesis touches upon how international agreements handled the matter with a review of bi and multilateral agreements as well as the impacts for its signatories. In light of these agreements, we study Brazil's actions within the international regulation of the issue, as it has only one international agreement in effect with Portugal, in which it confers Portuguese citizen equal treatment as Brazilians when purchasing land in Brazil. Still within international laws, this thesis discusses the phenomenon of land appropriation (known internationally as land grab, land grabbing or farmland grab), the question that it raises, the affected regions and researches developed by international organizations. From this analysis, researches made in Brazil and internationally that touch upon economic, social and environmental development in face of land appropriation by foreigners are presented, while also discussing Brazil's understanding of it. In conclusion, Brazil's regulation of foreign investment should be reformulated in order to bring more security by filling and removing gaps of divergent interpretations.
\end{abstract}

Keywords: Foreign Investment, Land, Brazil, International Law, Development. 


\section{SUMÁRIO}

LISTA DE ABREVIAÇÕES

Erro! Indicador não definido.

INTRODUÇÃO 7

1. Evolução Histórica do Investimento Estrangeiro Em Terras no Brasil........... Erro! Indicador não definido.

1.1 Século XVI e Empresa Agrícola Portuguesa .....Erro! Indicador não definido.

1.2 Século XIX e Organização das Terras no Brasil-Império .Erro! Indicador não definido.

1.3 Constituição de 1891 e o Início do Século XXI Erro! Indicador não definido.

1.4 Regime Militar (1964-1985) ................................Erro! Indicador não definido.

2. O Investimento Estrangeiro - Definições e Conceitos ...........Erro! Indicador não definido.

2.1 Noção Econômica de Investimento Estrangeiro Erro! Indicador não definido.

2.2 Investimento Estrangeiro Pela Perspectiva Jurídica - A Constituição Federal de 1988

Erro! Indicador não definido.

2.2.1 Legislação Infraconstitucional......................Erro! Indicador não definido.

2.2.1.1 Banco Central e Registro do Capital Estrangeiro no Brasil .................Erro! Indicador não definido.

2.3 Definição de Investimento Estrangeiro Pela Legislação Nacional ...............Erro! Indicador não definido.

2.4 Nacionalidade da Pessoa Jurídica

Erro! Indicador não definido.

2.4.1 Nacionalidade da Pessoa Jurídica no Direito Internacional ..................Erro! Indicador não definido.

2.4.2 Nacionalidade da Pessoa Jurídica no BrasilErro! Indicador não definido.

2.5 Modalidades de Investimento Estrangeiro e Regime Jurídico...Erro! Indicador não definido.

2.5.1 Investimento Estrangeiro Direto (IED) .......Erro! Indicador não definido.

2.5.2 Investimento em Portfólio Erro! Indicador não definido.

3. Investimento Estrangeiro em Terras - Legislação e sua Interpretação .............Erro! Indicador não definido.

3.1 Limitação à Extensão do Imóvel Rural Adquirido por Estrangeiro Erro! Indicador não definido.

3.1.1 Zona Típica de Módulo (ZTM) ...................Erro! Indicador não definido.

3.1.2 MEI - Módulo de Exploração Indefinida...Erro! Indicador não definido.

3.1.3 Limitações Baseadas na Ocupação do Município .......Erro! Indicador não definido.

3.1.4 Loteamentos Rurais ....................................Erro! Indicador não definido. 
3.1.6 Aquisição de Propriedade por Sucessão Legítima ......Erro! Indicador não definido.

3.1.7 Áreas Indispensáveis à Segurança Nacional

Erro! Indicador não definido.

3.2. Faixa De Fronteira

Erro! Indicador não definido.

3.2.2 Terras Devolutas

Erro! Indicador não definido.

3.2.3 Restrições quanto às atividades desenvolvidas pelo estrangeiro.......... Erro! Indicador não definido.

3.3 Interpretação da Legislação ...............................Erro! Indicador não definido.

3.3.1 Pareceres da Advocacia-Geral União ..........Erro! Indicador não definido.

3.3.2 Parecer GQ-22, de 6 de junho de 1994........Erro! Indicador não definido.

3.3.3 Parecer GQ-181, de 22 de janeiro de 1999.Erro! Indicador não definido.

3.3.4 Parecer CGU/AGU 01/2008 - RVJ - Aprovado Pelo Parecer LA-01/2010

Erro! Indicador não definido.

3.3.5 Análise Jurisprudencial..............................Erro! Indicador não definido.

3.3.6 Análise da Matéria pelo Órgão Especial do Tribunal de Justiça do Estado de São Paulo.

Erro! Indicador não definido.

3.3.7 Parecer 461/12-E da Corregedoria Geral de Justiça do Tribunal de Justiça do Estado de São Paulo

Erro! Indicador não definido.

4. Aquisição De Terras Por Estrangeiros À Luz Do Direito Internacional .........Erro! Indicador não definido.

4.1 Evolução do Direito Internacional do Investimento Estrangeiro e Regime Jurídico Internacional

Erro! Indicador não definido.

4.2 Acordos Multilaterais ........................................Erro! Indicador não definido.

4.2.1 Acordo Geral Sobre Comércio de Serviços - GATS ...Erro! Indicador não definido.

4.2.2 NAFTA - North American Free Trade Agreement ...Erro! Indicador não definido.

4.2.3 União Europeia ............................................rro! Indicador não definido.

4.2.4 Mercado Comum do Sul - MERCOSUL.....Erro! Indicador não definido.

4.3 Acordos Bilaterais de Investimento (BITs - Bilateral Investment Treaties)

Erro! Indicador não definido.

4.4. Tratados Bilaterais celebrados pelo Brasil.........Erro! Indicador não definido.

4.4.1 Tratado de Amizade, Cooperação e Consulta entre a República Federativa do

Brasil e a República Portuguesa

Erro! Indicador não definido.

4.4.2 Acordo de Garantia De Investimentos com os Estados Unidos ........... Erro! Indicador não definido.

4.5 Segurança Nacional Em Legislações Nacionais Erro! Indicador não definido.

5. Desenvolvimento e Apropriação De Terras ...........Erro! Indicador não definido.

5.1 Direito ao Desenvolvimento e Investimento Estrangeiro ..Erro! Indicador não definido. 
5.2 Apropriação De Terras e Desenvolvimento........Erro! Indicador não definido.

5.3 Apropriação de Terras no Brasil .........................Erro! Indicador não definido.

5.3.1 Brasil Como Alvo Da Apropriação De Terras ............Erro! Indicador não definido.

5.3.2 Investimento Externo Brasileiro em Terras Estrangeiras .. Erro! Indicador não definido.



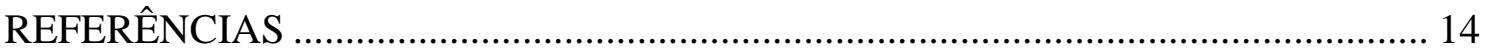




\section{INTRODUÇÃO}

$\mathrm{O}$ aumento de investimento estrangeiro em terras ${ }^{1}$ ficou evidente a partir de 2008, quando se verificou seu crescimento vertiginoso e despontou maior interesse sobre o tema. Segundo estimativas do Banco Mundial $^{2}$, foram celebrados acordos envolvendo a compra ou arrendamento de 56,6 milhões de hectares de terras no Mundo entre outubro de 2008 a agosto de 2009. Já com base nos dados capturados pela Land Matrix $^{3}$, com base em operações confirmadas e confiáveis ${ }^{4}$, estima-se que foram celebradas operações envolvendo 32,7 milhões de hectares de terras no Mundo no mesmo período ${ }^{5}$. Se comparado com os anos anteriores a 2008 , em que tais números ficavam bem abaixo de cinco milhões de hectares, é nítida a existência de um movimento global no referido período com vistas ao controle de terras. $\mathrm{O}$ alvo principal de tal investimento é o continente africano, que concentrou setenta por cento das operações de compra ou arrendamento de terras ${ }^{6}$.

Dados recentes apontam a origem do investimento como investidores privados, fundos de investimento soberanos, bem como Estados, tendo alguns o objetivo de garantir a segurança alimentar em países com escassez de terras cultiváveis, como a Arábia Saudita e os Emirados Árabes. O fenômeno da aquisição de largas extensões de terras por organizações ligadas a Estados soberanos deu origem ao conceito "land grab",

\footnotetext{
${ }^{1}$ No âmbito deste trabalho, entende-se por terras a propriedade em que a área é o principal elemento dela, em razão de seu aproveitamento ou possibilidade de aproveitamento, em qualquer atividade rural. Tal aproveitamento pode se dar, por exemplo, para a indústria extrativa, a agricultura ou a pecuária. Tal definição de terras foi baseada na definição utilizada pelo Decreto-Lei $n^{\circ} 2.610$, de 20 de Setembro de 1940. Não se compreende, portanto, na definição de terras, imóveis urbanos, mesmo que sua destinação seja como simples terrenos (destinados ou não à edificação), hortas ou jardins.

2 DEININGER, Klaus; BYERLEE, Derek. Rising Global Interest In Farmland - Can It Yield Sustainable and Equitable Benefits? Washington: Banco Mundial, 2011. Disponível em: <http://siteresources. worldbank.org/DEC/Resources/Rising-Global-Interest-in-Farmland.pdf>. Acesso em: 5 dez. 2014.

${ }^{3}$ A Land Matrix é uma organização que consolida informações sobre operações envolvendo investimento estrangeiro em terras. As operações noticiadas, necessariamente envolvem a transferência de direitos de uso, controle ou propriedade sobre terras por meio de venda, arrendamento ou concessões, que cubram uma área superior a 200 hectares e impliquem na potencial transformação de uma terá de produção pequena, de uma comunidade local ou importante para o ecossistema para um uso comercial. As informações começam a ser coletadas no ano 2000.

${ }^{4}$ Dada a falta de transparência nas operações envolvendo a compra e arrendamento de terras, não é possível confirmar todas as negociações que foram relatadas. Com base em negociações relatadas, tal número sobe para 83,2 milhões de hectares.

5 ANSEEUW, Ward; et al. Transnational Land Deals for Agriculture in the Global South - Analytical Report based on the Land Matrix Database. Disponível em: <http://www.oxfam.de/sites/www.oxfam.de/files/20120427_report_land_matrix.pdf>. Acesso em: 10 dez. 2014, p. vii.

${ }^{6}$ Ibidem, p. vii.
} 
traduzido neste trabalho para apropriação de terras $^{7}$ que, de forma resumida ${ }^{8}$, é o investimento estrangeiro no controle de vastas extensões territoriais, com o envolvimento de governos e que tragam alguma forma de risco à segurança alimentar do país receptor do investimento.

Tal fenômeno despertou também a preocupação das Nações Unidas, cujo Relator Especial para o Direito à Alimentação, Olivier DE SCHUTTER, durante seu mandato, de 2008 a julho de 2014, analisou de forma aprofundada a matéria e, portanto, vem noticiando a sua preocupação com a segurança alimentar e o desenvolvimento sustentável das áreas receptoras de investimentos.

Entretanto, a preocupação gerada pelo investimento estrangeiro não se restringe somente à África ${ }^{9}$. A imprensa brasileira também vem alardeando uma preocupação com tal forma de investimento no País ${ }^{10}$. Surgem, ainda, estudos de organizações internacionais como a Food and Agriculture Organization ("FAO") 11, apontando para a existência do fenômeno da apropriação de terras (land grab) na América do Sul, notadamente no Brasil e Argentina.

Os fatos acima não passaram despercebidos pelo Governo Brasileiro: A Advocacia-Geral da União (“AGU”), através de parecer recente ${ }^{12}$, alterou a sua

\footnotetext{
${ }^{7} \mathrm{O}$ capítulo 5 trata de forma mais aprofundado sobre os motivos que levaram à escolha da nomenclatura.

${ }^{8}$ Os critérios para definir "land grab" podem variar de acordo com o organismo que faz a análise, tais definições serão analisadas no capítulo 5. A definição na introdução é um resumo dos critérios utilizados pela FAO.

9 "Companhias de Agronegócios da Índia têm planos de investir US\$2,5 bilhões na aquisição ou aluguel de milhões de hectares de terras baratas na Etiópia, Tanzânia e Uganda, entrando na briga com chineses e outros governos para produção agrícola no exterior. (...) A ação indiana voltou a atrair a atenção para o fenômeno de "land grab", a aquisição de terras por governos e empresas estatais em outros países. Novo relatório da Organização das Nações Unidas para a Agricultura e Alimentação (FAO) estima que estrangeiros já compraram entre 50 milhões e 80 milhões de hectares principalmente na África, mas crescentemente também na América Latina." Valor Econômico. São Paulo, 29 de agosto de 2011. Disponível em: <http://www.valor.com.br/empresas/990616/empresas-da-india-querem-investir-emterras-na-africa>. Acesso em: 19 out. 2011.

${ }^{10}$ Neste sentido, notícia do Jornal "O Globo", de 27 abril de 2013: "RIBEIRÃO PRETO (SP) - Bandeiras estrangeiras, sobretudo americanas, francesas e inglesas, tremulam nos mastros das usinas de açúcar e álcool do Brasil, que iniciou esta semana na região de Ribeirão Preto, interior de São Paulo, a colheita da maior safra de cana-de-açúcar da História. Enfrentando uma crescente desnacionalização, o setor atingiu no ano passado uma marca impressionante: os estrangeiros foram responsáveis por $33 \%$ da produção brasileira de açúcar e álcool. Em 2010, a participação era de apenas 12\%. Em 2006, quando o processo de internacionalização começou, a presença dos estrangeiros era de somente 3\%. Nessa velocidade, a estimativa é que em breve o setor será totalmente dominado pelo capital externo, conforme levantamento da Datagro, empresa que presta consultoria à Organização Internacional do Açúcar." Disponível em: $<$ http://oglobo.globo.com/economia/estrangeiros-sao-nova-geracao-de-usineiros-8232513〉. Acesso em 03 jul. 2013.

${ }^{11}$ FAO. Dinámicas en el mercado de la tierra en América Latina y el Caribe. Santiago: FAO, 2011. Disponível em: <http://www.rlc.fao.org/fileadmin/content/events/semtierras/acaparamiento.pdf >. Acesso em: 8 dez. 2014.

${ }_{12}$ O Parecer CGU/AGU No 01/2008 - RVJ, emitido pela Consultoria Geral da União e aprovado pela Advocacia-Geral da União no Parecer LA-01, publicado em 23 ago. 2010 no Diário Oficial da União.
} 
interpretação da lei que regula a compra de imóveis rurais por estrangeiros. O resultado prático foi tornar a lei mais restritiva e buscar um maior controle das áreas adquiridas por investidores estrangeiros. A mudança de interpretação realizada pela AGU, a pedido da Presidência da República, é consequência de uma alegada preocupação com a segurança nacional, além do desenvolvimento econômico, social e sustentável das áreas receptoras dos investimentos, conforme expresso no próprio Parecer, cuja transcrição parcial é feita no capítulo 3, em que é realizada uma análise aprofundada.

Além disso, em razão dos fatores descritos acima, o Poder Legislativo se mobiliza no sentido de rever as leis que regulam o investimento estrangeiro em imóveis rurais no Brasil ${ }^{13}$. Tal movimento legislativo consiste na apresentação de projetos de lei visando a regular as restrições ao investimento estrangeiro em imóveis rurais. Em uma análise preliminar das motivações e de projetos de lei em trâmite, é possível identificar que muitos tomam como tema central a segurança nacional, o desenvolvimento sustentável, o desenvolvimento econômico e a proteção da fauna e flora nacional ${ }^{14}$.

$\mathrm{Na}$ mesma medida em que cresce o interesse de investidores estrangeiros, o montante do investimento e a sua relevância econômica, cresce também a relevância das normas a serem observadas por tais investimentos, suas restrições e os seus efeitos econômicos. Assim, um estudo acerca do investimento estrangeiro em terras, no atual contexto brasileiro, não pode se limitar a dissecar a legislação nacional, mas deve analisar também o Direito Internacional que vem sendo construído a respeito.

\footnotetext{
${ }^{13}$ Destaca-se dentre os Projetos de lei que tramitam no Congresso Nacional, o Projeto de Lei $n^{\circ} 228-2007$ do Deputado Beto Faro, que originalmente criava restrições à compra de terras por empresas brasileiras controladas por capital estrangeiro, tendo sido aprovado o Parecer do Deputado Marcos Montes ${ }^{13}$, que apresenta texto substitutivo, o qual não diferencia empresas brasileiras em razão da composição de seu capital. Ou seja, a aquisição ou arrendamento de imóveis rurais por empresas brasileiras controladas por capital estrangeiro, se aprovado o referido projeto de lei, passaria novamente a ser livre de restrição e controle. Até o fechamento deste texto (21 dez. 2014) o referido Projeto aguardava apreciação pelo Plenário da Câmara dos Deputados. CÂMARA DOS DEPUTADOS. Projeto de Lei 2289-2007. $<$ http://www.camara.gov.br/proposicoesWeb/fichadetramitacao?idProposicao=373948>. Acesso em 20 dez. 2012.

14 "No mérito, é inegável que se faz necessário um maior rigor legislativo no controle da posse e propriedade de imóveis rurais, diante das notícias de abusos na ocupação fundiária do território da Amazônia Legal, assim como da Faixa de Fronteira das regiões Norte e Centro-Oeste, por parte de estrangeiros, que se aproveitam da permissividade da atual disciplina legal sobre o tema para concentrar em suas mãos gigantescas glebas de terra, muitas vezes pirateando impunemente a biodiversidade do nosso País. Além disso, ameaçam a exploração sustentável e voltada para os interesses nacionais dos incalculáveis recursos estratégicos localizados nessas áreas, sobretudo os recursos minerais." Parecer da Comissão de Constituição, Justiça e Cidadania do Senado, sobre o Projeto de Lei da Câmara $\mathrm{n}^{\circ}$ 302, de 2009 ( $\mathrm{n}^{\circ}$ 4.440, de 2001, na origem), dos Deputados Nilson Mourão e José Dirceu, que "dispõe sobre a propriedade de imóveis rurais por pessoas estrangeiras na Amazônia Legal brasileira e altera as Leis números 5.709, de 7 de outubro de 1971, e 6.634, de 2 de maio de 1979”, Relator: Senador Antonio Carlos Junior. Aprovado em 7 de abril de 2010.
} 
Diante do movimento legislativo e as recentes alterações de entendimento nacionais e internacionais que serão analisadas nesta dissertação, tratar somente a legislação nacional, no atual contexto, significaria focar em um "moving target", ou seja, "mirar em um alvo móvel", desenvolvendo, portanto, um trabalho com prazo de validade. Desta forma, a pesquisa que se pretende desenvolver, não somente discorrerá a legislação nacional e o Direito Internacional sobre o investimento estrangeiro em terras, mas, preocupar-se-á também com um estudo dos fatores que motivam atualmente as discussões a respeito.

Um dos grandes ativos do Brasil é sua vasta extensão territorial e sua riqueza em recursos naturais, sendo essencial que a forma de exploração de tal riqueza seja regulamentada de forma clara e objetiva, em consonância com os princípios internacionais sobre a matéria. As restrições ao investimento estrangeiro em imóveis rurais no Brasil geram consequências que extrapolam o âmbito jurídico da questão, radiando efeitos por toda a economia e sociedade.

Portanto, o estudo representado neste trabalho possui uma importância considerável tanto jurídica quanto econômica. No atual cenário econômico e político brasileiro, uma análise aprofundada do assunto se torna uma rica fonte de conhecimento para discussão da matéria e construção da legislação. 


\section{CONCLUSÕES}

Verificou-se nesta dissertação, inicialmente, que o investimento estrangeiro em terras no Brasil historicamente tem passado por movimentos pendulares. Enquanto Colônia, o pêndulo estava totalmente do lado da restrição, procurando proteger e resguardar o monopólio da capital. Com a chegada da Família Real ao Brasil e abertura gradual dos portos, o pêndulo foi movido no sentido da liberalização. Atingiu-se o ápice da liberação no final do século XIX, em que era incentivada a vinda de estrangeiros com a promessa de terras, muito embora, como visto, a legislação tenha sido moldada para dificultar o acesso do imigrante a ela - o que pode ter acarretados atrasos ao desenvolvimento do País.

Já do início até a metade do século XX, o investimento estrangeiro em terras passa novamente a sofrer restrições implementadas em leis esparsas, estabelecendo-se o marco da legislação aplicada a ele até hoje. Entretanto, a regulação da primeira metade do século XX não impediu a aquisição de vastas extensões territoriais durante o regime militar (1964-1985). No início da década de 1990, com a Emenda Constitucional n ${ }^{\circ}$ 6/1995 e a abertura dos mercados, retoma-se um movimento de liberalização estabelecido em interpretações da legislação pela AGU.

Em 2010, com a publicação da nova interpretação da AGU acerca da aplicação das restrições ao investimento estrangeiro em terras da Lei 5.709/1971, é retomada a restrição. Enquanto isso, aguarda-se a resolução do debate no Poder Legislativo, onde não há um consenso acerca da equação entre os efeitos benéficos e os possíveis impactos negativos da atração de capitais estrangeiros para a lavoura brasileira.

Tal discussão não é restrita ao Poder Legislativo, ela também é travada no patamar global. No que tange a uma das principais questões levantadas, a determinação da nacionalidade da pessoa jurídica, o Direito Internacional continua discutindo os critérios para sua definição nos trabalhos de elaboração de uma Convenção Internacional sobre Proteção Diplomática.

Além disso, não se chegou ainda a uma decisão quanto aos efeitos do investimento estrangeiro em terras, principalmente diante do medo da insegurança alimentar nas áreas receptoras, que tem assombrado em maior grau o continente africano, levando ao fenômeno da apropriação de terras (conhecido como "Land Grab" ou "Land Grabbing", em inglês). 
A América do Sul, por ser rica em área cultivável e ter atraído a atenção do capital internacional (principalmente do oriente médio e Ásia), foi igualmente alvo da preocupação quanto à ocorrência de apropriação de terras por estrangeiros. Entretanto, o regime de terras na América do Sul é diferente do adotado em muitos países africanos, pois como verificado, a terra cultivável em tais países pertence ao Governo. Aliado a isso, tem-se identificado uma onda de investimentos regionais, ao contrário do que acontece na África. Muito embora se detecte a existência de interesses e investimentos do Oriente Médio e da Ásia, os investimentos oriundos de países da própria América do Sul é que estão tomando a dianteira quando se trata de investimento estrangeiro em terras no Brasil e demais países da América do Sul e América Central.

O caso do Brasil é ainda mais emblemático, em virtude de sermos apontados tanto como alvo de apropriação de terras regionais, bem como investidores em outras partes do mundo. O Brasil é identificado como apropriador de terras inclusive na África, em que vozes já estão ecoando em protesto ao investimento brasileiro em Moçambique. E os investimentos estrangeiros no Brasil, tão alardeados pela imprensa nos últimos anos, após análise dos números apresentados e da legislação, parecem-nos não apresentar um quadro tão obscuro até o momento, como se poderia imaginar.

Apesar disso, a posição que o Brasil tem adotado no contexto do Direito Internacional dos Investimentos Estrangeiros é evitar a abertura das lavouras brasileiras ao capital externo. Somente ao capital português é permitido livre acesso às terras brasileiras por meio do Tratado de Amizade celebrado com Portugal. Não obstante a existência de tentativas de organização e liberalização de investimentos estrangeiros no Brasil, consistentes nos Protocolos de Colônia e Buenos Aires no Mercosul e nos BITs celebrados nos anos 1990, verifica-se que todos eles não saíram do papel, tendo sido barrados no Congresso Nacional.

O Direito Internacional consuetudinário não coloca restrições ao poder do Estado de legislar sobre a entrada do investimento estrangeiro em seu território. O Direito Internacional tem influência sobre a forma de indenização ao estrangeiro que teve suas terras expropriadas, não constituindo a expropriação em si uma violação ao Direito Internacional do Investimento Estrangeiro. Já a restrição à entrada do investimento é de competência da legislação doméstica de cada Estado ${ }^{15}$, sendo possível observar os mais variados graus de liberalização ou restrição ao investimento

${ }^{15}$ RECHTSTEINER, Beat Walter. Beschränkung des Grundstückerwerbs durch Ausländer. Zürich: Schulthess Polygraphischer, 1985, p. 3. 
estrangeiro em tais legislações, conforme se verifica da análise dos compromissos assumidos pelos países membros do GATS.

Muito embora, a legislação sobre investimentos estrangeiros em terras ainda seja uma seara que desperta a preocupação dos demais Estados, os acordos regionais já demonstram uma tendência de liberalização do investimento, como observado no NAFTA e na União Europeia. As restrições ao investimento estrangeiro em terra em tais blocos econômicos, quando existentes e aplicadas, são feitas em caráter de transição para um regime de liberalização de capitais.

Ademais, os princípios norteadores do investimento estrangeiro em terras que vem sendo desenvolvidos por organismos internacionais, mostram que o investimento pode trazer consequências benéficas quando bem administrado e regulamentado. As conclusões iniciais dos estudos recentes do Banco Mundial também apontam nesta mesma direção. Entretanto, pouca atenção tem sido dada no Brasil a tais fatos, tendo grande parte da imprensa preferido destacar compras isoladas de terras por estrangeiros como alarmantes.

Diante disso, o Brasil deve, primeiramente, adotar uma posição clara com relação à aquisição de terras por estrangeiros. As constantes mudanças de interpretação, aliada à batalha entre a União e o Estado de São Paulo, por exemplo, é uma demonstração da insegurança jurídica que a atual lei traz.

Conclui-se, portanto, que o mundo avança na direção de uma liberalização de capitais, inclusive na área do investimento estrangeiro em terras. Contudo, ainda é necessária uma mobilização do Direito Internacional para estabelecer mais claramente as bases em que tais investimentos devem ser feitos, reunindo-se os princípios estabelecidos por organismos internacionais e a soft law produzida, de forma a propiciar o desenvolvimento sustentável da região receptora, sem que se condene ela à miséria ou que os danos ao meio ambiente superem quaisquer vantagens que ela possa auferir. As discussões continuam e o Direito Internacional está construindo tais bases, enquanto isto a posição da legislação brasileira reflete a espera por um consenso. 


\section{REFERÊNCIAS}

ACCIOLY, Hildebrando. Tratado de Direito Internacional Público. V. I - São Paulo: Quartier Latin, 2009.

ACCIOLY, Hildebrando. SILVA, G. E. do Nascimento e CASELLA, Paulo Borba. Manual de Direito Internacional Público. 19 ed. São Paulo: Saraiva, 2011.

ALBUQUERQUE, José Lindomar. Conflito e integração nas fronteiras dos "brasiguaios". Salvador: Cad. CRH, v. 23, n. 60, 2010, pp. 579-590.

ALLE, Saulo Stefanone. Linhas diretrizes da OCDE para as empresas multinacionais e sua implementação no Brasil. 2013. Dissertação (Mestrado em Direito Internacional) Faculdade de Direito, Universidade de São Paulo, São Paulo, 2013. Disponível em: <http://www.teses.usp.br/teses/disponiveis/2/2135/tde-15082013-100756/>. Acesso em: 20 dez. 2014.

ALMEIDA, Paulo Roberto de. "Os Investimentos Estrangeiros e a Legislação Comercial Brasileira No Século XIX: Retrospecto Histórico" in "Formação da Diplomacia Econômica no Brasil: as relações econômicas internacionais no Império". São Paulo-Brasília: Editora Senac-SP/Funag, 2001.

ALVIM, Augusto Mussi. Investimentos estrangeiros diretos e suas relações com os processos, causas e efeitos da concentração e estrangeirização das terras no Brasil. Projeto de cooperação técnica "Apoio às políticas e à participação social no desenvolvimento rural" (PCT IICA/NEAD). Brasília: NEAD, 2009 (relatório de pesquisa).

ANDRADE, Thiago; FONTOURA COSTA, José Augusto. Direito, desenvolvimento e o investimento estrangeiro direto: critica ao padrão de indenização por danos perpetrados pelo Estado conforme o direito brasileiro. In SCHAPIRO, Mario G.; TRUBEK, David M. (orgs.). Direito e desenvolvimento: Um diálogo entre os BRICS. São Paulo: Saraiva, 2012

ANDREZO, Andrea Fernandes, LIMA, Iran Siqueira. Mercado financeiro - aspectos históricos e conceituais. São Paulo: Pioneira, 1999.

ANSEEUW, Ward; et al. Transnational Land Deals for Agriculture in the Global South

- Analytical Report based on the Land Matrix Database. Disponível em: http://www.oxfam.de/sites/www.oxfam.de/files/20120427_report_land_matrix.pdf. Acesso em: 10 dez. 2014. 
ASTORGA, Ricardo Letelier. The Nationality of Juridical Persons in the ICSID Convention in Light of Its Jurisprudence. Países Baixos: Max Planck Yearbook Of United Nations Law, Vol. 11, 2007, p. 417-472

BANCO CENTRAL. Resolução 3.844 de 23 de março de 2010. Disponível em: $<$ https://www3.bcb.gov.br/normativo/detalharNormativo.do?N=110024192\&method=al harNormativo> Acesso em: 20 dez. 2014.

Circular do Banco Central no 3.689, de 16 de dezembro de 2013. Disponível em: <http://www.bcb.gov.br/pre/normativos/circ/2013/pdf/circ_3689_v1_O.pdf>. Acesso em: 20 dez. 2014.

Circular 3.691, de 16 de dezembro de 2013. Disponível em: $<$ http://www.bcb.gov.br/pre/normativos/busca/normativo.asp?tipo=circ\&ano=2013\&nu mero=3691>. Acesso em: 20 dez. 2014.

RDE-IED: Manual do Declarante. 2014. Disponível em: <http://www.bcb.gov.br/ftp/infecon/RDE/ManualRDE-IED.pdf>. Acesso em: $21 \mathrm{dez}$. 2014.

BANCO MUNDIAL. The Practice Of Responsible Investment Principles In Largerscale Agricultural Investments: Implications for Corporate Performance and Impact on Local Communities. World Bank Report Number 86175-GLB. Washington D. C.: 2014. Disponível em: <http://unctad.org/en/PublicationsLibrary/wb_unctad_2014_en.pdf>. Acesso em: 7 dez. 2014.

BARRAL, Welber. A influência do comércio internacional no processo de desenvolvimento. In: BARRAL, Welber e PIMENTEL, Luiz Olavo (coord.). Comércio Internacional e Desenvolvimento, Florianópolis: Boiteux, 2006.

BARBOSA, Denis Borges. Direito do desenvolvimento industrial: Direito de acesso do capital estrangeiro. Licitações, subsídios e patentes. Rio de Janeiro: Lumen Juris, 1996.

BARROS, Alexandre Mendonça de, PESSÔA, André (Orgs.). Impactos Econômicos do Parecer da AGU (Advocacia Geral da União), que impõe restrições à aquisição e arrendamento de terras agrícolas por empresas brasileiras com controle do capital detido por estrangeiros. São Paulo: Agroconsult e MB Agro, 2011.

BORRAS JR., Saturnino M.; KAY, Cristóbal; GÓMEZ, Sérgio; WILKINSON, John. Land Grabbing and global capitalist accumulation: key features in Latin America. Canadian Journal of Development Studies. Toronto: Canadian Journal of Development Studies 33(4): 402-16, 2012a. Disponível em: 
<http://www.tandfonline.com/doi/abs/10.1080/02255189.2012.745394\#.VIZInDHF9cA >. Acesso em: 8 dez. 2014;

BORRAS JR., Saturnino M.; FRANCO, Jennifer C.; KAY, Cristóbal; GÓMEZ, Sérgio; SPOOR, Max. Land Grabbing in Latin America and the Caribbean. The Journal of Peasant Studies, Voluma 39, Edição 3-4, páginas 845-872, 2012b. Disponível em: <http://www.tandfonline.com/doi/abs/10.1080/03066150.2012.679931\#.VIZJ0zHF9cA >. Acesso em: 8 dez. 2014;

BORRAS JR., Saturnino M.; FRANCO, Jennifer C.; KAY, Cristóbal; SPOOR, Max. Land Grabbing in Latin America and the Caribbean Viewed from Broader International Perspectives. Santiago: Trabalho apresentado no seminário "Dinámicas en el mercado de la tierra en América Latina y el Caribe", 2011. Disponível em: $<$ http://www.tni.org/report/land-grabbing-latin-america-and-caribbean-broaderinternational-perspectives-0>. Acesso em: $8 \mathrm{dez} .2014$ (BORRAS et all, 2012b).

BRASIL. Decreto-lei $\mathrm{n}^{\circ}$ 2.711, de 18 de dezembro de 1860. Disponível em: http://www.planalto.gov.br/CCIVIL_03/decreto/Historicos/DIM/DIM2711.htm. Acesso em: 13 set. 2014.

Decreto de 25 de novembro de 1808. Disponível em: <http://www.planalto.gov.br/ccivil_03/revista/Rev_48/dim251808.htm>. Acesso em 1 dez. de 2014.

Lei 601 de 18 de setembro de 1850. Disponível em: <http://www.planalto.gov.br/ccivil_03/Leis/L0601-1850.htm>. Acesso em: 30 nov. 2014.

Lei $\mathrm{n}^{\mathrm{o}}$ 581, de 4 de setembro de 1850. Disponível em: <http://www.planalto.gov.br/ccivil_03/Leis/LIM/LIM581.htm>. Acesso em 30 nov. 2014.

Decreto 1.318 de 30 de janeiro de 1854. Disponível em: <http://www.planalto.gov.br/ccivil_03/decreto/1851-1899/D1318.htm>. Acesso em: 14 dez. 2014.

. Constituição Da República Dos Estados Unidos Do Brasil, de 24 de Fevereiro de 1891. Disponível

em: <http://www.planalto.gov.br/ccivil_03/constituicao/Constituicao91.htm>. Acesso em 1 dez. 2014. 
. Decreto $\mathrm{n}^{\circ}$ 19.924, de 27 de abril de 1931. Disponível em: <http://legis.senado.gov.br/legislacao/ListaNormas.action?numero=19924\&tipo_norma $=$ DEC\&data=19310427\&link=s $>$. Acesso em: 1 de dez. de 2014.

. Decreto Decreto-Lei $\mathrm{n}^{\circ}$ 1.164, de 18 de Março de 1939. Disponível em: <http://www2.camara.leg.br/legin/fed/declei/1930-1939/decreto-lei-1164-18-marco1939-349147-publicacaooriginal-1-pe.html>. Acesso em: 1 dez. de 2014.

Decreto-Lei $\mathrm{n}^{\mathrm{o}} 1.202$ de 08 de abril de 1939. Disponível em: <http://www2.camara.leg.br/legin/fed/declei/1930-1939/decreto-lei-1202-8-abril-1939349366-publicacaooriginal-1-pe.html>. Acesso em: 1 de dez. de 2014.

Decreto-Lei $\mathrm{n}^{\mathrm{o}}$ 1.968, de 17 de Janeiro de 1940. Disponível em: <http://www2.camara.leg.br/legin/fed/declei/1940-1949/decreto-lei-1968-17-janeiro1940-411939-publicacaooriginal-1-pe.html>. Acesso em: 1 dez. de 2014.

Decreto-Lei $\mathrm{n}^{\mathrm{o}}$ 2.009, de 9 de Fevereiro de 1940. Disponível em: <http://www2.camara.leg.br/legin/fed/declei/1940-1949/decreto-lei-2009-9-fevereiro1940-411911-publicacaooriginal-1-pe.html>. Acesso em: 1. dez. 2014.

. Decreto-Lei $\mathrm{n}^{\mathrm{o}} 2.610$ de 20 de setembro de 1940. Disponível em: <http://www2.camara.leg.br/legin/fed/declei/1940-1949/decreto-lei-2610-20-setembro1940-412701-publicacaooriginal-1-pe.html>. Acesso em: 1 dez. 2014.

. Decreto-Lei $\mathrm{n}^{\circ}$ 3.059, de 14 de fevereiro 1941. Disponível em: <http://www2.camara.leg.br/legin/fed/declei/1940-1949/decreto-lei-3059-14-fevereiro1941-413001-publicacaooriginal-1-pe.html>. Acesso em: 1 dez. 2014.

Decreto-Lei $\mathrm{n}^{\circ}$ 6.430, de 17 de Abril de 1944. Disponível em: <http://www2.camara.leg.br/legin/fed/declei/1940-1949/decreto-lei-6430-17-abril1944-452643-publicacaooriginal-1-pe.html>. Acesso em: 1 de dez. de 2014.

Decreto-Lei $\mathrm{n}^{\mathrm{o}}$ 3.438, de 17.07.1941. Disponível em: <http://www.planalto.gov.br/ccivil_03/decreto-lei/1937-1946/Del3438.htm>. Acesso em: 1 dez. 2014.

Emenda Constitucional $\mathrm{n}^{\mathrm{o}} 10$ de 10 de novembro de 1964. Disponível em: <http://www2.camara.leg.br/legin/fed/emecon/1960-1969/emendaconstitucional-10-9novembro-1964-364969-publicacaooriginal-1-pl.html>. Acesso em: 2 dez. 2014.

Lei Delegada de $\mathrm{n}^{\circ} 11$ de 11 de outubro de 1962. Disponível em: <http://www.planalto.gov.br/ccivil_03/leis/ldl/ldl11.htm>. Acesso em: 2 de Dez. de 2014. 
Código Civil de $1916 . \quad$ Disponível em: <http://www.planalto.gov.br/ccivil_03/leis/13071.htm>. Acesso em: 2 de Dez. de 2014. Ato Institucional $n^{\circ} 5$ (AI-5) de 13 de dezembro de 1968. Disponível em: <http://www.planalto.gov.br/ccivil_03/AIT/ait-05-68.htm>. Acesso em: 2 dez. 2014.

Ato Complementar $\mathrm{n}^{\mathrm{o}} 45$ de 30 de janeiro de 1969. Disponível em: <http://www.planalto.gov.br/ccivil_03/ACP/acp-45-69.htm>. Acesso em: 2 dez. 2014.

Decreto-Lei $\mathrm{n}^{\circ}$ 494, de 10 de março de 1969. Disponível em: <http://www.planalto.gov.br/ccivil_03/Decreto-Lei/1965-1988/Del0494.htm>. Acesso em: 2 dez. 2012.

- Decreto-Lei $\mathrm{n}^{\mathrm{o}}$ 924, de 10 de outubro de 1969. Disponível em: <http://www.planalto.gov.br/ccivil_03/decreto-lei/1965-1988/Del0924.htm>. Acesso em: 2 dez. 2014.

. Lei $\mathrm{n}^{\mathrm{o}}$ 5.709, de 7 de outubro de 1971. Disponível em: <http://www.planalto.gov.br/ccivil_03/leis/L5709.htm>. Acesso em 2 dez. 2014.

. Emenda Constitucional $\mathrm{n}^{\circ} 6$ de 15 de agosto de 1995. Disponível em: <http://www.planalto.gov.br/ccivil_03/constituicao/Emendas/Emc/emc06.htm>. Acesso em: 29 nov. 2014.

- Decreto $\mathrm{n}^{\circ}$ 21.798, de 6 de setembro de 1932. Disponível em: $<$ http://legis.senado.gov.br/legislacao/ListaTextoIntegral.action?id=34326>. Acesso em 22 out. 2014.

. Decreto $\mathrm{n}^{\mathrm{o}} 123$ de 11 de novembro de 1892. Disponível em: <http://www2.camara.leg.br/legin/fed/decret/1824-1899/decreto-123-11-novembro1892-541377-publicacaooriginal-44941-pl.html>. Acesso em: $21 \mathrm{dez} .2014$.

Decreto $\mathrm{n}^{\mathrm{o}} 2.304$ de 2 de julho de 1896. Disponível em: <http://www2.camara.leg.br/legin/fed/decret/1824-1899/decreto-2304-2-julho-1896540279-publicacaooriginal-40293-pe.html>. Acesso em: 21 dez. 2014.

. Lei $\mathrm{n}^{\mathrm{o}}$ 12.376, de 30 de dezembro de 2010. Disponível em: <http://www.planalto.gov.br/ccivil_03/_Ato2007-2010/2010/Lei/L12376.htm>. Acesso em: 21 dez. 2014.

Lei 4.728, de 14 de julho de 1965. Disponível em: <http://www.planalto.gov.br/ccivil_03/leis/14728.htm>. Acesso em: 21 dez. 2014. . Constituição Federal de 1946, promovida por meio da Emenda Constitucional n ${ }^{\circ}$ 10 à referida Constituição. Vide: 
<http://www.planalto.gov.br/ccivil_03/constituicao/Constituicao46.htm\#art5xva>. Acesso em 04 out. 2014.

. Lei Complementar $\mathrm{n}^{\mathbf{0}}$ 73, de 10 de fevereiro de 1993. Disponível em: <http://www.planalto.gov.br/ccivil_03/leis/lcp/lcp73.htm>. Acesso em: 20 dez. 2014.

Decreto $\mathrm{n}^{\circ} 1.110$ de 9 de julho de 1970, resultou no INCRA - Instituto Nacional de Colonização e Reforma Agrária. Disponível em: <http://www.planalto.gov.br/ccivil_03/decreto-lei/1965-1988/Del1110.htm>. Acesso em: 22 dez. 2014.

. Decreto $\mathrm{n}^{\mathrm{o}}$ 18.871, de 13 de Agosto de 1929. Disponível em: <http://www2.camara.leg.br/legin/fed/decret/1920-1929/decreto-18871-13-agosto1929-549000-publicacaooriginal-64246-pe.html>. Acesso em: 16 dez. 2014.

Constituição Federal de 1964. Disponível em: <http://www.planalto.gov.br/ccivil_03/constituicao/Constituicao91.htm>. Acesso em 14 out. 2014.

Decreto 10.105, de 5 de março de 1913. Disponível em <http://www2.camara.leg.br/legin/fed/decret/1910-1919/decreto-10105-5-marco-1913575772-norma-pe.html>. Acesso em: 14 out. 2014.

Decreto-Lei 9.760, de 5 de setembro de 1946. Disponível em: Disponível em: <http://www.planalto.gov.br/ccivil_03/decreto-lei/del9760.htm>. Acesso em: 21 dez. 2014.

Ministério do Desenvolvimento Agrário. Instrução Normativa Conjunta $n^{\circ} 1$, de 27 de setembro de 2012. Disponível em: <http://www.incra.gov.br/index.php/estruturafundiaria/regularizacao-fundiaria/aquisicaode-terras-por-estrangeiros/file/1503instrucao-normativa-conjunta-n-01-27-09-2012>. Acesso em 03 jul. 2013.

. Proposta de Emenda Constitucional no 5/1995, de 16 de fevereiro de 1995. Disponível em: <http://www.camara.gov.br/proposicoesWeb/fichadetramitacao?idProposicao=24957>. Acesso em 14 out. 2014.

Decreto $\mathrm{n}^{\mathrm{o}}$ 591, de 6 de julho de 1992. Disponível em: <http://www.planalto.gov.br/ccivil_03/decreto/1990-1994/D0591.htm>. Acesso em 28 nov. 2014.

- Decreto $\mathrm{n}^{\mathrm{o}} 57.943$ de 10 de março de 1966. Disponível em: <http://www2.camara.gov.br/legin/fed/decret/1960-1969/decreto-57943-10-marco1966-398440-publicacaooriginal-1-pe.html>. Acesso em: 4 dez. 2014. 
Decreto $\mathrm{n}^{\mathrm{o}}$ 21.798, de 6 de setembro de 1932. Disponível em: $<$ http://legis.senado.gov.br/legislacao/ListaTextoIntegral.action?id=34326>. Acesso em 22 out. 2014.

Parecer n ${ }^{\circ}$ LA 01, de 19 de agosto de 2010 da Advocacia-Geral da União. Aprovado em: 19 ago. 2010.

Parecer GQ-22, de 6 de junho de 1994. <https://sistema.planalto.gov.br/asprevweb/exec/parecerAGU181.cfm>. Acesso em: 20 dez. 2014.

Parecer GQ-181, de 22 de janeiro de 1999. $<$ https://sistema.planalto.gov.br/asprevweb/exec/parecerAGU181.cfm>. Acesso em: 20 dez. 2014.

- Decreto $\mathrm{n}^{\mathrm{o}}$ 3.927, de 19 de setembro de 2001. Disponível em: http://www.planalto.gov.br/ccivil_03/decreto/2001/D3927.htm. Acesso em: 20 dez. 2014.

BRITO, José Gabriel de Lemos. Pontos de partida para a história econômica do Brasil. $3^{\text {a }}$ ed. São Paulo: Editora Nacional, 1980.

BROWNLIE, Ian. Principles of Public International Law. $6^{\mathbf{a}}$ ed. Oxford: Oxford University Press, 2003.

CÂMARA DOS DEPUTADOS. Projeto de Lei 2289-2007. <http://www.camara.gov.br/proposicoesWeb/fichadetramitacao?idProposicao=373948.

> Acesso em 20 dez. 2012

CASELLA, Paulo Borba. International Development Law and the right to Development in Post-Modern international Law In: TOUFAYAN, Mark; TOURMEJOUANNET, Emmanuelle; RUIZ-FABRI, Hélène. Droit international et nouvelles approches sur le tiers-monde: entre répétition et renouveau $=$ international law and new approaches to the third world: between repetition and renewal. Paris : Société de législation comparée, 2013.

CASTRO, Ana Célia. As Empresas Estrangeiras no Brasil - 1860-1913. Dissertação de Mestrado em Economia. Unicamp: Campinas, 1976.

CIDH. Caso Comunidad Indígena Sawhoyamaxa Vs. Paraguay. Sentencia de 29 de março de 2006. Disponível em: <http://www.corteidh.or.cr/docs/casos/articulos/seriec_146_esp2.pdf>. Acesso em: 22 nov. 2014. 
CIJ. Nottebohm case (Lichtenstein VS. Guatemala). Segunda Fase. Julgado em 6 abr. 1955. Disponível em: <http://www.icj-cij.org/docket/files/18/2674.pdf>. Acesso em: 07 nov. 2014.

. Case concerning the Barcelona Traction, Light and Power Company, Limited. Julgado em: 5 fev. 1970. Disponível em: <http://www.icj-

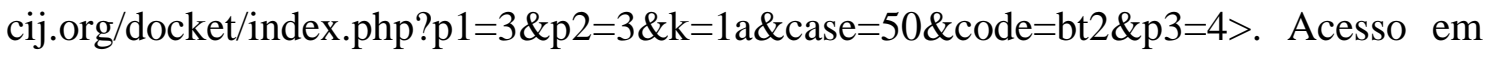
08 nov. 2014.

Case concerning elettronica sicula s.p.a. (elsi) (United States of America v. Italy). Julgado em 20 jul. 1989. Disponível em: <http://www.icjcij.org/docket/files/76/6707.pdf>. Acesso em 08 nov. 2014.

CIRDI. Tokio Tokelés vs. Ukraine. Caso $\mathrm{n}^{\circ} \mathrm{ARB} / 02 / 18$. Decision on Jurisdiction. Julgado em 29 abr. 2004. Disponível em: $<$ https://icsid.worldbank.org/ICSID/FrontServlet?requestType=CasesRH\&actionVal=sh owDoc\&docId=DC639_En\&caseId=C220>. Acesso em: 21 dez. 2014.

CONFEDERAÇÃO NACIONAL DA INDÚSTRIA - CNI. Circular "Integração Internacional". Ano 1, Vol. 4, Abril/Junho de 2009. Disponível em: <http://www.cni.org.br/portal/lumis/portal/file/fileDownload.jsp?fileId=FF808081239C 15120123A03D694C6CC8>. Acesso em 23 nov. 2014.

CORRÊA, Alexandre Augusto de Castro. Rui e a doutrina drago. Revista da Faculdade de Direito, Universidade de São Paulo, [S.1.], v. 62, n. 1, p. 267-282, dez. 1966, p. 271. Disponível em: <http://www.revistas.usp.br/rfdusp/article/view/66547/69157>. Acesso em: 13 dez. 2014.

CPJI. The Mavrommatis Palestine Concessions. Leiden: A. W. Sijthoff, n. 2, 1924. Série A. Disponível em: <http://www.icjcij.org/pcij/serie_A/A_02/06_Mavrommatis_en_Palestine_Arret.pdf $>$. Acesso em 23 nov. 2014

CPJI. Case concerning the factory at Chorzow - Indemnity - Merits. Leiden: A. W. Sijthoff, n. 17, 1928. Série A. Disponível em: <http://www.icj-cij.org/pcij/series-ab.php?p1=9\&p2=3>. Acesso em 25 nov. 2014.

CYSNEIROS, Vicente Cavalcanti. O Estrangeiro e a Propriedade Rural. - Porto Alegre: Editor Sérgio Antônio Fabris, 1985.

DE SCHUTTER, Olivier. The Green Rush: The Global Race for Farmland and the Rights of Land Users. Harvard International Law Journal, vol. 52(2). Cambridge: 
2011(a), pp. 503-559. Disponível em: <http://www.harvardilj.org/2011/07/issue_522_de-schutter/>. Acesso em 30 nov. 2014.

How not to think of land-grabbing: three critiques of large-scale investments in farmland. The Journal of Peasant Studies, 38:2, P. 249-279, 2011(b). Disponível em: <http://www.tandfonline.com/doi/abs/10.1080/03066150.2011.559008\#.VHtH7jHF874 >. Acesso em: 30 nov. 2014;

Large-scale land acquisitions and leases: A set of core principles and measures to address the human rights challenge. Organização das Nações Unidas. Genebra: [s.n.] 2009.

DEININGER, Klaus; BYERLEE, Derek. Rising Global Interest In Farmland - Can It Yield Sustainable and Equitable Benefits? Washington: Banco Mundial, 2011. Disponível em: <http://siteresources.worldbank.org/DEC/Resources/Rising-GlobalInterest-in-Farmland.pdf>. Acesso em: 5 dez. 2014.

DIAS, Bernadete de Figueiredo. Investimentos estrangeiros no Brasil e o direito internacional. Curitiba: Juruá, 2010.

DOLINGER, Jacob. Direito Internacional Privado: Parte Geral. 10ª Ed. Rio de Janeiro: Forense, 2012.

ESTADO DE SÃO PAULO, O. Maioria dos brasileiros vive irregularmente fora do País. São Paulo, 20 set. $2010 . \quad$ Disponível em: $<$ http://www.estadao.com.br/noticias/geral,maioria-dos-brasileiros-vive-irregularmentefora-do-pais,615498>. Acesso em: 9 dez. 2014.

- Acordo define destino dos brasileiros na Bolívia. São Paulo, 6 out. 2009. Disponível em: <http://politica.estadao.com.br/noticias/geral,acordo-define-destino-dosbrasileiros-na-bolivia,446919>. Acesso em: 9 dez. 2014.

ESTADOS UNIDOS DA AMÉRICA. 2012 U.S. Model Bilateral Investment Treaty. Disponível em: <http://www.ustr.gov/sites/default/files/BIT\%20text\%20for\%20ACIEP\%20Meeting.pdf >. Acesso em 23 nov. 2014.

9 (7 U.S.C. 3508). Disponível em: <http://www.ag.senate.gov/download/agricultural-foreign-investment-disclosure-act> Acesso em: 14 dez. 2014.

- Defense Production Act, 1950. Disponível em: <http://www.fema.gov/medialibrary-data/20130726-1650-20490-5258/final_defense_production_act_091030.pdf>. Acesso em: 14 dez. 2014. 
Foreign Investment and National Security Act, 2007. Disponível em: $<$ http://www.treasury.gov/resource-center/international/foreigninvestment/Documents/FINSA.pdf>. Acesso em: 14 dez. 2014.

FAO, Dinámicas en el mercado de la tierra en América Latina y el Caribe. Santiago do Chile: 2011.

http://www.rlc.fao.org/fileadmin/content/events/semtierras/acaparamiento.pdf. Acesso em: 8 de Dez. de 2014.

- Statutory recognition of customary land rights in Africa. Roma, 2010. Disponível em: <http://www.fao.org/docrep/013/i1945e/i1945e00.htm>. Acesso em: 14 dez. 2012.

- Foreign Agricultural Investment Country Profile - Nigeria. Roma, 2012.

Disponível

em:

$<$ http://www.fao.org/fileadmin/user_upload/tcsp/docs/Nigeria_Country_Profile_FINAL .pdf>. Acesso em: 14 dez. 2014.

- Voluntary Guidelines on the esponsible Governance of Tenure of Land, Fisheries and Forests in the Context of National Food Security. Roma, 2012. Disponível em: 〈http://www.fao.org/docrep/016/i2801e/i2801e.pdf〉. Acesso em: 9 dez. 2014.

- Diretrizes Voluntárias: em apoio à realização progressiva do direito à alimentação adequada no contexto da segurança alimentar nacional. Roma, 2012. Disponível em: <http://www.sesc.com.br/mesabrasil/doc/Diretrizes.pdf>. Acesso em: 9 dez. 2014.

FERRARI FILHO, Fernando; SILVA, Gustavo Teixeira Ferreira da; SCHATZMANN, Samira. Políticas comercial e cambial, vulnerabilidade externa e crescimento econômico: a experiência da economia brasileira a partir dos anos 1980. Nova econ.[online]. 2011, vol.21, n.1 [cited 2013-06-30], pp. 11-43. Available from: $\quad<$ http://www.scielo.br/scielo.php?script=sci_arttext\&pid=S010363512011000100001\&lng=en\&nrm=iso>. Acesso em: $21 \mathrm{dez} .2014$.

FERREIRA, Pinto. Curso de Direito Agrário. $5^{\text {a }}$ Ed. São Paulo: Saraiva, 2002.

FIDALGO, José Davi Lós Reis. A Retificação do Registro e O Georreferenciamento. Trabalho de Graduação Individual - Faculdade de Direito - Universidade Presbiteriana Mackenzie, São Paulo, 2005.

FONTOURA COSTA, José Augusto. Direito Internacional do Investimento Estrangeiro. 1. Ed. Curitiba: Juruá, 2010. 
Proteção e promoção do investimento estrangeiro no Mercosul uma ferramenta para a implementação de um bom clima de investimentos?. Revista Brasileira de Política Internacional. v. 49, n. 2. Brasília: 2006. Disponível em $<$ http://www.scielo.br/scielo.php?script=sci_arttext\&pid=S0034-

3292006000200004\&lng=pt\&nrm=iso>. Acesso em: 27 nov. 2014.

FURTADO, Celso. Formação Econômica do Brasil. 34 ${ }^{\text {a }}$ Ed. São Paulo: Companhia das Letras, 2007.

FREYRE, Gilberto. Casa-grande \& Senzala: formação da família brasileira sob o regime da economia patriarcal. 51 ${ }^{\text {a }}$ Ed. São Paulo: Global, 2006.

GARCIA, Paulo. Terras devolutas: defesa possessória, usucapião, registro torrens ação discriminatória. Belo Horiztone: Livraria Oscar Nicolai, 1958.

GARRIDO FILHA, Irene. O Projeto Jari e os Capitais Estrangeiros na Amazônia. 2a ed. Petrópolis: Editora Vozes, 1980.

GEAMPAULO, Victor Lordani. Engenho São Jorge dos Erasmos: aproximações acerca da morte e da vida no complexo açucareiro vicentino (séculos XVI-XVII). 2013. Dissertação (Mestrado em História Social) - Faculdade de Filosofia, Letras e Ciências Humanas, Universidade de São Paulo, São Paulo, 2013. Disponível em: <http://www.teses.usp.br/teses/disponiveis/8/8138/tde-30042013-104452/>. Acesso em: 2014-09-01; http://www.prceu.usp.br/engenho/. Acesso em 01.09.2014 às 21:30h.

GLOBO, O. Estrangeiros são a nova geração de usineiros. Rio de Janeiro, 27 abr. 2013. Disponível em: <http://oglobo.globo.com/economia/estrangeiros-sao-nova-geracao-deusineiros-8232513>. Acesso em 03 jul. 2013.

GRAIN. World Bank report on land grabbing: beyond the smoke and mirrors. 08 set. 2011. Disponível em: <http://www.grain.org/article/entries/4021-world-bank-report-onland-grabbing-beyond-the-smoke-and-mirrors>. Acesso em: 7 dez. 2014.

GRUPO DE TRABALHO EM DESENVOLVIMENTO E MEIO AMBIENTE NAS AMÉRICAS. Globalização, Investimento Estrangeiro e Globalização. Disponível em: <http://ase.tufts.edu/gdae/Pubs/rp/FDI_WG_Oct08_Portug_Full.pdf>. Acesso em 28 ago. 2014

GUIMARAES, Samuel Pinheiro. Capital nacional e capital estrangeiro. Estud. Av., São Paulo, v. 14, n. 39, $2000 . \quad$ Disponível em $<$ http://www.scielo.br/scielo.php?script=sci_arttext\&pid=S0103$40142000000200011 \& \operatorname{lng}=\mathrm{en} \& \mathrm{nrm}=\mathrm{iso}>$. Acesso em 28 ago. 2014 
GUPTA, Joyeeta; GRIJP, Nicolien van der; KUIK, Onno. Climate Change, Forests and REDD: Lessons for Institutional Design. New York: Routledge, 2013.

HAGE, Fábio; PEIXOTO, Marcus; e FILHO, José Eustáquio Vieira. Retrocesso sobre aquisição e arrendamento de terras por estrangeiros: o Estado é soberano e não perde o controle da ocupação do território. Disponível em: <http://www.srb.org.br/modules/news/article.php?storyid=5658>. Acesso em 02 jul. 2013.

HAUSMANN, Ute; KÜNNEMANN, Rolf. Globalising economic and social human rights by strengthening extraterritorial state obligations - Germany's extraterritorial human rights obligations. Outubro, 2006, p. 15. Disponível em: <http://www.eed.de/fix/files/doc/eed_Germanys_extraterritorial_human_rights_06_eng. pdf>. Acesso em: 22 nov. 2014.

HODGSON, Steven; CULLINAN, Cormac; CAMPBELL, Karen. Land ownership and Foreigners: a comparative analysis of regulatory approaches to the acquisition and use of land by foreigners. FAO Legal Papers On-line $n^{\circ}$ 5, 1999. 16. Disponível em: <http://www.fao.org/fileadmin/user_upload/legal/docs/lpo6.pdf >. Acesso em: $20 \mathrm{dez}$. 2014.

INCRA. Instrução Especial/INCRA/Nº5-A, de 6 de junho de 1973, devidamente alterada pela Instrução Especial INCRA nº 50, de 26 de agosto de 1997. Disponível em: http://www.incra.gov.br/sites/default/files/uploads/institucionall/legislacao--/atosinternos/instrucoes/ie5a_060673.pdf. Acesso em: 20 dez. 2014.

Manual de Orientação Para Aquisição e Arrendamento de Imóvel Rural por Estrangeiro, aprovado pela Norma de Execução INCRA/nº 108, de 02 de outubro de 2013, publicada no $\mathrm{BS} \mathrm{n}^{\circ} 40$, de 07 de outubro de 2013. Disponível em: <http://www.incra.gov.br/media/politica_fundiaria/aquisicao_e_arrendamento_de_terra _por_estrangeiro/manual_de_orientacao_aquisicao_imovel_rural_estrangeiro.pdf >. Acesso em: 22 dez. 2014.

Instrução Normativa INCRA no 76 de 23 de agosto de 2013. Disponível em: $<$ http://www.incra.gov.br/institucionall/legislacao--/atos-internos/instrucoes/file/1579instrucao-normativa-n-76-23-08-13>. Acesso em: 23 dez. 2014.

KELSEN, Hans. Teoria Geral do Direito e do Estado (tradução de Luís Carlos Borges). São Paulo: Martins Fontes, 2000.

KÜNZLI, Willi Sebastian. The Equator Principles: Soft Law in International Project Finance. Berkeley: Traveaux - Berkeley International Law Journal, 2013. Disponível 
em: $\quad<$ http://berkeleytravaux.com/equator-principles-soft-law-international-projectfinance/>. Acesso em: 9 dez. 2014.

LEHAVI, Amnon. Article: The Global Law of the Land. University of Colorado Law Review, edição 425: Colorado, 2010.

LEMES, Selma Maria Ferreira. Mercosul e Nafta - Os acordos de proteção e Promoção de Investimentos. A Solução de Controvérsias por Arbitragem. IN: "A Arbitragem na Era da Globalização”. GARCEZ, José. (org.). Rio de Janeiro: Forense, $2^{\circ}$ ed. 1999. p. 215-253.

LUIS, Daniel Tavela. Proteção do investimento estrangeiro: o sistema do Centro Internacional para a Resolução de Disputas Relativas ao Investimento (CIRDI) e suas alternativas. 2013. Dissertação (Mestrado em Direito Internacional) - Faculdade de Direito, Universidade de São Paulo, São Paulo, 2013. Disponível em: <http://www.teses.usp.br/teses/disponiveis/2/2135/tde-08012014-084342/>. Acesso em: 2014 dez. 22.

MARCHETTI, Renata Auxiliadora. Capital Estrangeiro no Brasil: registro e intervenção do Estado nos contratos privados. São Paulo: Atlas, 2009.

MARTIN, Antoine; AYALEW, Mulugeta M. Acquiring Land Abroad for Agricultural Purposes: 'Land Grab' or Agri-FDI? Report of the Surrey International Law Centre and Environmental Regulatory Research Group. Surrey Law Working Paper No. 08/2011. Guildford, 2011. Disponível em: <http://ssrn.com/abstract=1788948>. Acesso em: 7 de Dez. de 2014

MENDES, José Sacchetta Ramos. Desígnios da Lei de Terras: imigração, escravismo e propriedade fundiária no Brasil Império. Cad. CRH [online]. 2009, vol.22, n.55, pp. 173-184. Disponível em: http://www.scielo.br/pdf/ccrh/v22n55/11.pdf. Acesso em: 30 nov. 2014.

MENDES, José Sacchetta Ramos. Laços de Sangue. Privilégios e Intolerãncia à Imigração Portuguesa no Brasil (1822-1945). Edição brasileira.. 1. ed. São Paulo: Editora da Universidade de São Paulo (EDUSP), 2011. v. 1.

MERCOSU. Protocolo De Colonia Para A Promoção E A Proteção Recíproca De Investimentos No Mercosul (Intrazona). MERCOSUL/CMC/DEC. $\mathrm{N}^{\mathrm{o}} 11$, 1993. Disponível em: 〈http://www.sice.oas.org/trade/mrcsrs/decisions/DEC1193p.asp>. Acesso em: 20 dez. 2014.

MERLET, M. Les appropriations de terres à grande échelle: analyse du phénomène et propositions d'orientations. Paris: Comité Foncier et Développement, 2010. 
MESSIAS, Junqueira. As Terras Devolutas na Reforma Agrária. São Paulo: Revista dos Tribunais, 1964.

MEXICO. Constitución Política De Los Estados Unidos Mexicanos, 5 de febrero de 1917. Disponível em: http://www.diputados.gob.mx/LeyesBiblio/htm/1.htm. Acesso em: 20 nov. 2014.

MITTAL, Anuradha. The 2008 Food Price Crisis: Rethinking Food Security Policies.

G-24 Discussion Paper No. 56, 2009. Disponível em: <http://unctad.org/en/Docs/gdsmdpg2420093_en.pdf>. Acesso em 28 nov. 2014.

NAFTA. Anexo II - Reservas para Futuras Medidas. Disponível em: $<$ https://www.nafta-sec-

alena.org/Default.aspx?tabid=97\&ctl=SectionView\&mid=1588\&sid=f7947ad4-4c5a483f-b778-04d4c84dc610\&language=en-US>. Acesso em 20 nov: 2014

OCDE. Glossary of Foreign Direct Investment Terms and Definitions. In OECD Benchmark Definition of Foreign Direct Investment. $4^{\mathrm{a}}$ ed. Disponível em: <http://www.oecd.org/investment/investmentfordevelopment/2487495.pdf>. Acesso em 26 ago. 2014.

OLIVA, Milena Donato. Do Negócio Fiduciário à Fidúcia. São Paulo: Atlas, 2014.

OLIVEIRA, Ariovaldo Umbelino. A questão da aquisição de terras por estrangeiros no Brasil - um retorno aos dossiês. Agrária (São Paulo. Online), [S.1.], n. 12, p. 3-113, jun. 2010. Disponível em: <http://www.revistas.usp.br/agraria/article/view/702>. Acesso em: 02 dez. 2014.

ONU. A Declaração sobre o Direito ao Desenvolvimento. Res. 41/128 da Assembleia Geral das Nações Unidas em 4 de dezembro de 1986. Disponível em <http://www.un.org/Depts/dhls/>. Acesso em: $22 \mathrm{dez} .2014$.

- Resolution adopted by the General Assembly 3202 (S-VI). Programme of Action on the Establishment of a New International Economic Order. Disponível em: <http://www.un-documents.net/s6r3202.htm>. Acesso em 19 out. 2014.

- Declaration on the Establishment of a New International Economic Order. Resolution adopted by the General Assembly 3201 (S-VI). Disponível em: <http://www.un-documents.net/s6r3201.htm>. Acesso em: 19 out. 2014.

- Carta das Nações Unidas de 26 de junho de 1945. Disponível em: <http://nacoesunidas.org/carta/>. Acesso em: 20 dez. 2014.

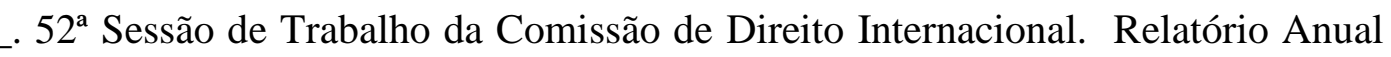
da Comissão de Direito Internacional. Volume II. Disponível em: 
<http://legal.un.org/ilc/publications/yearbooks/Ybkvolumes(e)/ILC_2000_v2_p2_e.pdf >. Acesso em: 08 nov. 2014.

. Comissão de Direito Internacional. Ata da Reunião de Número 2416, de 13 de julho de 1995.2 Disponível em: <http://legal.un.org/ilc/documentation/english/a_cn4_sr2416.pdf>. Acesso em 09 nov. 2014.

Ata da Sessão da Assembleia Geral de 26 de janeiro de 1996. disponível em: $<$ http://daccess-ddsny.un.org/doc/UNDOC/GEN/N96/762/07/PDF/N9676207.pdf?OpenElement>. Acesso em 09 nov. 2014.

- Proposta de Convenção sobre Proteção Diplomática. Disponível em: <http://legal.un.org/ilc/texts/9_8.htm>. Acesso em: 09 nov. 2014.

. Resolução da Assembleia Geral da ONU n. 1.514, de 14 de dezembro de 1960. Disponível em: <http://www.un.org/en/decolonization/declaration.shtml>. Acesso em: 20 dez. 2014.

Programme of Action on the Establishment of a New International Economic Order. Resolution adopted by the General Assembly 3202 (S-VI). Disponível em: <http://www.un-documents.net/s6r3202.htm>. Acesso em 19 out. 2014.

A Declaração sobre o Direito ao Desenvolvimento. Res. 41/128 da Assembleia Geral das Nações Unidas em 4 de dezembro de 1986. Disponível em <http://www.un.org/Depts/dhls/>. Acesso em: 20 out. 2014.

PÉREZ, Mamerto; SCHLESINGER, Sergio; WISE, Timothy A. Promessas e Perigos da Liberalização do Comércio Agrícola - As Lições da América Latina. Rio de Janeiro: Action Aid e Instituto para o Desenvolvimento Global e Meio Ambiente (GDAE), 2008 .

PERRONE-MOISÉS, Cláudia. Direitos ao Desenvolvimento e Investimentos Estrangeiros. São Paulo: Oliveira Mendes, 1998.

PRETTO, José Miguel. Imóveis rurais sob propriedade de estrangeiros no Brasil. Relatório de Projeto de cooperação técnica “Apoio às políticas e à participação social no desenvolvimento rural” (PCT IICA/NEAD), Brasília: NEAD (relatório de pesquisa), 2009.

Disponível

em:

http://www.coptec.org.br/biblioteca/Realidade\%20Brasileira/Artigos/terras\%20na\%20 m\%E3o\%20de\%20ESTRANGEIROS-pretto.pdf. Acesso 
QIN, Xiaojing. Foreigners' Right to Acquire Land under International Economic Agreements. Volume 8, Issue 1. Manchester: Manchester Journal of International Economic Law, 2011.

RECHTSTEINER, Beat Walter. Beschrankunger des grundstucke rwerbs durch aulander -- Zurich : Schulthess Polygraphischer, 1985.

REUTERS BRASIL. Grupo argentino El Tejar lidera em produção de soja no Brasil. 1 jul. 2011. Disponível em: <http://br.reuters.com/article/topNews/idBRSPE7600KX20110701>. Acesso em: 08 jun. 2012.

ROCHA, Olavo Acyr de Lima. Revista de Direito Agrário. Ano 16, n. ${ }^{\circ}$ 13. Brasília: INCRA, 2000.

RODAS, João Grandino. Sociedade comercial e Estado. São Paulo: Editora da Universidade Estadual Paulista: Saraiva, 1995.

SALOMÃO FILHO, Calixto. Regulação, Desenvolvimento e Meio Ambiente. In SALOMÃO FILHO, Calixto (Org.). Regulação e Desenvolvimento - Novos Temas. São Paulo, Malheiros, 2012.

; FERRÃO, Brisa Lopes de Mello; e RIBEIRO, Ivan César. Concentração, Estruturas e Desigualdade: As origens coloniais da pobreza e da má distribuição de renda. São Paulo: Idcid, 2006.

SARTI, Fernando; LAPLANE, Mariano. F. O investimento direto estrangeiro e a internacionalização da economia brasileira nos anos 90. Economia e Sociedade, v. 11, n. 1 (18), p. 129-164, jan./jun. 2002.

SHAH, Anup. Global Food Crisis 2008. 2008. Disponível em: <http://www.globalissues.org/article/758/global-food-crisis-2008>. Acesso em 28 nov. 2014.

SAUER, Sérgio; LEITE, Sergio Pereira. Expansão agrícola, preços e apropriação de terra por estrangeiros no Brasil. Rev. Econ. Sociol. Rural, Brasília, v. 50, n. 3, Sept. 2012 . Disponível em: http://www.scielo.br/scielo.php?script=sci_arttext\&pid=S010320032012000300007\&lng=en\&nrm=iso. Acesso em: 8 dez. 2014.

SAUTCHUK, Jaime; CARVALHO, Horácio Martins de; GUSMÃo, Sérgio Buarque de. Projeto Jari: A Invasão Americana. 6ª ed. São Paulo: Editora Brasil Debates, 1979 SCHAFFNIT-CHATTERJEE, Claire. Foreign investment in farmland No lowhanging fruit. Frankfurt am Main: Deutsche Bank - DB Research, 13 de Nov. de 2012. 
Disponível em: <https://www.dbresearch.com/PROD/DBR_INTERNET_ENPROD/PROD0000000000296807.pdf>. Acesso em: 9 dez. 2014.

SMALLER, Carin; MANN, Howard. A Thirst for Distant Lands: Foreign investment in agricultural land and water. International Institute for Sustainable Development (IISD), $2009 . \quad$ Disponível em: <http://www.iisd.org/pdf/2009/thirst_for_distant_lands.pdf>. Acesso em: 17 dez. 2014.

SORNARAJAH, M. The International Law on Foreign Investment. $3^{\mathrm{a}}$ ed. Nova Iorque: Cabridge University Press, 2010

STRENGER, Irineu. Direito Internacional Privado. 3ª edição. São Paulo: Ltr, 1996.

SUPERIOR TRIBUNAL DE JUSTIÇA. REsp 1416406/CE. Relator: Min. Humberto Martins. $2^{\text {a }}$ turma. Data do Julgamento: 14 out. 2014. DJe 24 out. 2014

SUPREMO TRIBUNAL FEDERAL. Sessão Plena. MS no 11.189 DF. Relator: Min.

Candido Motta Filho. Data do Julgamento: 3 abr. 1963. Disponível em: <http://redir.stf.jus.br/paginadorpub/paginador.jsp?docTP=AC\&docID=109934>.

Acesso em: 20 dez. 2014.

THE JERUSALEM POST. Foreign Nationals limited from purchasing ownership of land. Jerusalem, 29 mar. 2011. Disponível em: <http://www.jpost.com/NationalNews/Foreign-nationals-limited-from-purchasing-ownership-of-land>. Acesso em: 14 dez. 2014.

TORRES, Alessandra Valéria da Silva; SILVA, Conceição Luís Antônio Guerra. Aquisição de Terras por Estrangeiros - Legislação Comparada. Brasília: Câmara dos Deputados - Consultoria Legislativa, 2011, p. 12. Disponível em: <http://bd.camara.leg.br/bd/handle/bdcamara/12498>. Aceso em: 15 dez. 2014.

TRIBUNAL DE JUSTIÇA DO ESTADO DE SÃO PAULO. Órgão Especial do Tribunal de Justiça do Estado de São Paulo. Acórdão proferido em Mandado de Segurança número 0058947-33.2012.8.26.000. Julgado em 12 de setembro de 2012.

- Parecer 250/10-E - Corregedoria do Tribunal de Justiça do Estado de São Paulo. Disponível em: <http://s.conjur.com.br/dl/parecer-2502010-corregedoria-tjsp.pdf>. Acesso em: 20 dez. 2014.

TRIBUNAL DE JUSTIÇA DA UNIÃO EUROPEIA. Klaus Konle v. Austria - Case C-302/97. Julgamento em: 01 jun. 1999. Disponível em: <http://www.biicl.org/files/1862_c-302-97.pdf>. Acesso em: 20 dez. 2014.

UNCTAD. Towards a New Generation of International Investment Policies: UNCTAD's Fresh Approach to Multilateral Investment Policy-Making. UNCTAD IIA 
Issues Note No. 5. Genebra: 2013. Disponível em: <http://unctad.org/en/PublicationsLibrary/webdiaepcb2013d6_en.pdf>. Acesso em: 17 dez. 2014.

- Investment Policy Framework For Sustainable Investment. Genebra: 2010.

Disponível em: <http://unctad.org/en/publicationslibrary/webdiaepcb2012d6_en.pdf>. Acesso em: 20 dez. 2014.

- World Investment Reprt: global value chains: investment and trade for development. Nova Iorque e Genebra: 2013, p. 109. Disponível em: <http://unctad.org/en/publicationslibrary/wir2013_en.pdf>. Acesso em: 23 nov. 2014.

- The Principles for Responsible Agricultural Investment (PRAI), Genebra: 2010. Disponível em: <http://unctad.org/en/Pages/DIAE/G-20/PRAI.aspx>. Acesso em: 9 dez. 2014.

. Inter-agency working group on the food security pillar of the G20 Multi-year action plan on development. Options For Promoting Responsible Investment in Agriculture. Report to the High-Level Development Working Group. Genebra: 2011. Disponível em: <http://unctad.org/sections/dite_dir/docs//diae_dir_201106_G20_en.pdf>. Acesso em: 9 dez. 2014.

UNIÃO EUROPEIA. Tratado sobre o Funcionamento da União Europeia. Disponível em: 〈http://europa.eu/pol/pdf/qc3209190ptc_002.pdf〉. Acesso em: 20 nov. 2014.

Written Question No. 3216/97 by Mark WATTS to the Commission. Restrictions on purchase of property in EU Member States. OJ C 134, 30.4.1998, p. 115 $(F I, \quad S V) . \quad$ Disponível em: <http://eur-lex.europa.eu/legalcontent/EN/TXT/?qid=1416517899892\&uri=CELEX:91997E003216>. Acesso em 20 nov. 2014.

Tratado de Maastricht de 1992. Disponível em: <http://eurlex.europa.eu/legal-content/PT/TXT/?uri=uriserv:OJ.C_.1992.191.01.0001.01.POR>. Acesso em: 20 nov. 2014.

VALOR ECONÔMICO. Empresas da índia querem investir em terras na África. São Paulo, 29 ago. 2011. Disponível em: <http://www.valor.com.br/empresas/990616/empresas-da-india-querem-investir-emterras-na-africa>. Acesso em: 19 out. 2011.

VARGAS, Jorge A. Acquisition of Real Estate in Mexico by U.S. Citizens and American Companies. San Diego: San Diego Legal Studies Paper No. 07-85, 2007. Disponível em: http://ssrn.com/abstract=968704. Acesso em: 14 dez. 2014. 
VATTEL, Emer de. O direito das gentes I Vattel; prefácio e tradução: Vicente Marotta Rangel. Brasília: Editora Universidade de Brasília: Instituto de Pesquisa de Relações Internacionais, 2004.

ZERBINI, Eugenia Cristina Godoy de Jesus. O regimento internacional dos investimentos - sistemas regional, multilateral, setorial e bilateral (balanço da década de 1990, seguido do estudo de dois casos: o Mercosul e o projeto da ALCA). 2003. Tese (Doutorado em Direito Internacional) - Faculdade de Direito, Universidade de São Paulo, São Paulo, 2003. Disponível em: <http://www.teses.usp.br/teses/disponiveis/2/2135/tde-22112007-073410/>. Acesso em: 2014-10-18.

ZOOMERS, Annelies. Globalisation and the foreignisation of space: seven processes driving the current land grab. Londres: The Journal of Peasant Studies, 37(2), 2010. p. 429-47.

Páginas eletrônicas consultadas:

http://www.ibge.gov.br http://investmentpolicyhub.unctad.org/IIA

http://farmlandgrab.org http://www.oxfam.org.uk/get-involved/campaign-with-us/our-campaigns/grow/guideto-land-grabs?cid=rdt_land http://www.prosavana.com http://www.incra.gov.br http://treaties.un.org 